\title{
Identidades en movimiento. Familias chilenas en la fruticultura del Alto Valle de Río Negro, Argentina*
}

\author{
Verónica Trpin ${ }^{* * *}$
}

\begin{abstract}
Resumen
Este artículo, basado en el trabajo de campo realizado en áreas rurales del Alto Valle de Río Negro, Argentina, desde el año 1999, tiene como propósito presentar las relaciones en las cuales se insertan hombres y mujeres chilenas que residen y trabajan en "chacras" destinadas a la producción frutícola. Las diferentes actividades en las chacras se organizan según el sexo y la edad, definiéndose una segmentación del mercado de trabajo en la que se ven involucrados los diferentes miembros de la familia. Como desarrollaré, ser trabajadores chilenos en la fruticultura del Alto Valle de Río Negro reproduce una identidad étnica y nacional en el seno de la cotidianeidad familiar y laboral.
\end{abstract}

Palavras-chave: Migración Chilena, Familias, Fruticultura Trabajo Rural, Identidad Étnica y Nacional.

\footnotetext{
* Recebido para publicação em maio de 2007, aceito em agosto de 2007 (Revisão: Martha Ramirez-Gálvez).

*** Antropóloga, docente de la Universidad Nacional del Comahue, Argentina, y Becaria Doctoral Interna del CONICET - Universidad Nacional de Misiones. vtrpin@ciudad.com.ar
}

cadernos pagu (29), julho-dezembro de 2007:227-255. 
Identidades en movimiento

Identities in Movement.

Chilean Families in the Fruit Production of the

Alto Valle de Río Negro, Argentina

\begin{abstract}
This article, based on field work conducted in rural areas of the Alto Valle de Río Negro, Argentina, from 1999 on, analyzes the relations in which Chilean men and women who reside and work in small farms destined to fruit production are inserted. The different activities in the small farms are organized according to sex and age, circumscribing a segment of the labor market in which different members of the family are involved. As I will demonstrate, to be a Chilean worker in the fruit growing region of the Alto Valle is to reproduce an ethnic and national identity through work routines mediated by family relations.
\end{abstract}

Key Words: Chilean Migration, Families, Fruit Production, Rural Labor, Ethnic and National Identity. 
Verónica Trpin

\section{Introducción}

Este artículo, basado en el trabajo de campo realizado en áreas rurales del Alto Valle de Río Negro desde el año 1999, tiene como propósito presentar las relaciones en las cuales se insertan hombres y mujeres chilenas que residen y trabajan en "chacras" destinadas a la producción frutícola.

Si bien la producción de peras y manzanas para la exportación se caracteriza por absorber principalmente mano de obra masculina, las mujeres provenientes de Chile desde su llegada al Alto Valle han participado en la reproducción de la cotidianeidad de las familias trabajadoras. Su presencia en la chacras puede observarse en el desarrollo de tareas culturales consideradas "más livianas" o de menor calificación, y por ende de menor remuneración, en el cuidado de huertas y en la cría de animales como cerdos, conejos y gallinas, además de cubrir en su totalidad la responsabilidad de las tareas domésticas y la crianza de los hijos. Así, dentro de las chacras se mantiene una división de tareas basada en el género que se sustenta en una "naturalización" de los papeles de hombres y mujeres ${ }^{2}$, aunque ello no implica que los lugares atribuidos a cada uno de los integrantes de la familia sean absolutamente rígidos.

La selección de familias como unidad de análisis se vincula a que, tal como señalara, las diferentes actividades en las chacras se organizan según el sexo y la edad, definiéndose una segmentación del mercado de trabajo en la que se ven involucrados los diferentes miembros de la familia. En el caso que nos ocupa los grupos domésticos coinciden con la familia nuclear, enredada - como veremos - en una extensa red de relaciones.

\footnotetext{
1 Unidades productivas de referencia destinadas a la producción de peras y manzanas.

2 Estos fenómenos han sido observados en otras producciones rurales de América Latina (Abramo y Ranger, 1998; López y otros, 1999; Stolen, 2004; Brumer y Piñeiro, 2005).
} 
Identidades en movimiento

E. Woortmann (1995) advierte que las tradiciones marxistas que abordaron la problemática rural, o más específicamente campesina (Chayanov, Galeski y Tepicht) han aportado en considerar a los grupos domésticos como unidades de producción y consumo, sin dar cabida a los modos en que reproduce socialmente la familia. Por otro lado, considera que autores provenientes de la antropología al atender las relaciones de parentesco en los espacios rurales han considerado cómo las familias no sólo producen un producto, sino también deben recrear las condiciones sociales para reproducir su cotidianeidad. En este sentido es que Gabriela Schiavoni (1998:1) sostiene que

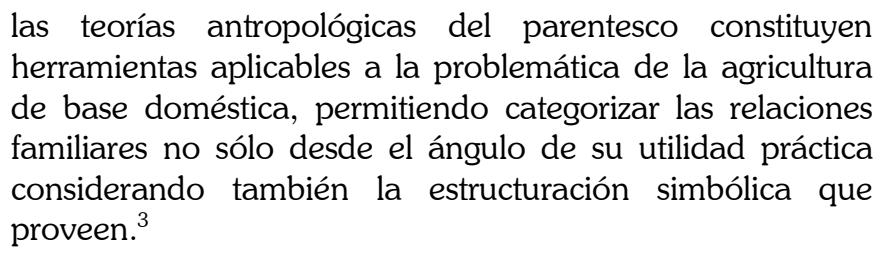

En las chacras del Alto Valle las familias migrantes se constituyen así en soporte productivo dentro de los predios de los patrones, al tiempo que son hombres y mujeres emparentadas que cotidianamente reproducen su condición de familia trabajadora. En la llegada al Alto Valle de Río Negro por referencias de un pariente, en la transmisión de los modos de realizar un trabajo hasta entonces desconocido y en el mantenimiento de lazos con sus familiares en Chile y en la zona, se evidencia el protagonismo que adquiere la familia como referencia laboral e identitaria. Tal como desarrollaré, ser trabajadores chilenos en la fruticultura del Alto Valle de Río Negro se reproduce en el seno de la cotidianeidad familiar y laboral.

\footnotetext{
3 Bourdieu (1991) ha sostenido parte de su crítica al estructuralismo de LéviStrauss al considerar el parentesco en términos de relaciones prácticas o estrategias concientes o inconscientes organizadas en un tipo de estructura social.
} 
El abordaje de las relaciones y prácticas de las familias migrantes en el Alto Valle de Río Negro se realizó a través de la etnografía. La observación participante y las entrevistas permitieron elaborar una descripción de condiciones y definiciones sociales que no quedan plasmadas en documentos escritos u oficiales, así como recuperar representaciones de lo que piensan y dicen la variedad de sujetos partícipes de la dinámica rural (Guber, 2001). El método etnográfico posibilitó asimismo atender cómo las definiciones de ser hombres y mujeres migrantes configuran las relaciones dentro de las chacras.

\section{La migración de chilenos y chilenas al Alto Valle}

La zona conocida como Alto Valle de Río Negro, en el norte de la Patagonia Argentina, se caracteriza desde principios del siglo $\mathrm{XX}$ por la producción intensiva de manzanas y peras, y en menor medida fruta de carozo y vid, inicialmente en predios de entre 5 y 10 hectáreas, llamadas chacras. ${ }^{4}$ Desde entonces, este Valle se ha constituido en un polo de atracción de migración limítrofe de origen chilena que se mantuvo hasta fines del siglo XX. El acceso a la propiedad estuvo limitado a migrantes de origen europeo, como españoles e italianos, delineándose una división del trabajo en la que los chacareros "son blancos y europeos" mientras que la mano de obra empleada en la explotación frutícola fue durante décadas chilena o de descendencia chilena, de piel y cabello más oscuro.

La vinculación entre el origen nacional chileno y una inserción laboral y residencial en las chacras como peones ha sido

\footnotetext{
${ }^{4}$ La presencia de estas unidades productivas hoy prácticamente ha sido desplazada por una predominancia de chacras de mayor extensión (de más de 20 hectáreas) y por la presencia en la producción primaria de empresas que controlan el empaque, frío y comercialización de la fruta, observándose un proceso de concentración de la propiedad y desaparición de pequeños productores. Estos cambios han repercutido notablemente en la organización del trabajo rural, situación que no será abordada en el presente trabajo, pero que actualmente son objeto de la investigación.
} 
Identidades en movimiento

una constante en la historia regional, dada la fluida vinculación entre sus poblaciones más allá de las definiciones políticas y barreras fronterizas impulsadas por los Estados desde principios del siglo XX (Bandieri, 2001). Las posibilidades laborales temporales que otorgaba la fruticultura en los momentos de mayor demanda de mano de obra como lo es la época de la cosecha, permitió absorber trabajadores migrantes que luego optaron por residir en la zona (Kloster, 1992).

La consolidación de las pequeñas y medianas producciones frutícolas constituyeron un mercado de trabajo en crecimiento en vista de la evolución de la superficie sembrada con frutales, el incremento de la productividad y el de las exportaciones. ${ }^{5}$ "El asalariado rural, antes mayoritariamente migrante y temporario, encontró opciones complementarias que le permitieron asentarse en forma definitiva" (Bendini y Radonich, 1999:43) junto a sus familias, evaluando las diferencias que podía hacer organizando sencillas divisiones del trabajo en su seno para incrementar la productividad y sus ingresos. ${ }^{6}$ Además, asentarse en la zona les permitía a los hombres realizar otros trabajos ligados, por ejemplo, a la construcción, en los períodos de baja demanda de mano de obra en las chacras; las mujeres ingresaron al empleo como domésticas o en la industria del empaque de fruta.

Sin embargo, como efecto de los índices de inflación registrados desde fines del 2001 en la Argentina, los ingresos fluctuantes de los trabajadores se han devaluado y parece no ser tan atractiva la migración hacia la zona. A estos cambios se suma la vigencia del registro obligatorio de los trabajadores rurales (RENATRE) desde 2002 - que implica la legalización de los

\footnotetext{
${ }^{5}$ Entre 1965 y 1980 la superficie de cultivo se incrementó en más de 20.000 hectáreas, mientras que la producción pasó, en el mismo período, de 424.600 toneladas de manzanas a 780.000 , debido a la incorporación de tecnología que maximizó la calidad de fruta de exportación.

${ }^{6}$ Es común que el jefe de familia realice la recolección de fruta de los árboles destinada a la empacadora mientras que las mujeres y los niños colaboran juntando fruta del piso que luego se destina a la industria.
} 
extranjeros - y las nuevas "competencias" y calificaciones laborales dentro de las chacras. Para el período 1980-1989 en el Alto Valle se registró la entrada de 6250 migrantes chilenos de más de 18 años, mientras que en el período 1990-2003 la cifra descendía a 1159 (INDEC, 2003).

La presencia de chilenos sigue siendo significativa en la zona, aunque no equiparable a los términos ascendentes registrados por otros flujos de migración limítrofe o latinoamericana en el país ${ }^{7}$. Según datos del INDEC del 2001, del total de migrantes limítrofes en la provincia de Río Negro (51.001 personas), los chilenos representan el $95.3 \%$. De un total poblacional de 552.822 en el año 2001, la población chilena asciende a 48.603, es decir, aproximadamente un $9 \%$ de la población que reside en esta provincia es de origen trasandino, constituyendo la fruticultura un nicho ocupacional caracterizado por la presencia de peones chilenos. ${ }^{8}$

No obstante, en el verano de 2005 no encontré los chilenos que venían cada temporada a realizar la cosecha en las chacras que frecuentaba en mi trabajo de campo.

La devaluación del peso en relación al dólar desde enero del 2002 repercutió en lo que estos migrantes evaluaban como la

7 Distintos estudios basados en el análisis de fuentes secundarias coinciden en que la proporción de pobladores de origen limítrofe que han emigrado a Argentina se ha mantenido constante, representando históricamente entre el 2 y el 3\% del total de la población (Benencia; 1999; Casaravilla; 1999). Los migrantes paraguayos de más de 18 años que llegaron a la Ciudad de Buenos Aires en el período 1980-1989 eran 8251, mientras que entre 1990 y 2003 ascendieron a 13.524; por su parte los bolivianos pasaron de 11.279 entre 1980 1989 a 21.812 entre 1990 y 2003 (INDEC, 2003).

8 Es preciso considerar que las fuentes estadísticas sólo reflejan cantidades de migrantes registrados por el censo, es decir, aquellos que son definidos por el estado a la vez que se autodefinen como extranjeros. Es así como escapan a estos datos otras situaciones que deben contemplarse: aquellos migrantes definidos como "ilegales", a los cuales no tuvo acceso el censista, y aquellos argentinos descendientes de migrantes que se autoadscriben y son adscriptos según el origen nacional de sus padres. 
Identidades en movimiento

oportunidad de "hacer una diferencia durante la cosecha en el Valle". Sin embargo, los controles de "blanqueo" y legalización del personal también constituyeron un factor que retrajo su presencia en la zona, especialmente de aquellos que permanecían en el Alto Valle en calidad de "turistas".

Los chilenos redujeron su llegada al Alto Valle en los últimos años aunque su presencia se mantiene como parte de la peonada efectiva en las chacras. En simultáneo, se expandió la llegada de los llamados trabajadores "norteños", provenientes de algunas provincias del norte de la Argentina, que se emplean como temporarios para la cosecha de fruta en el verano, pasando desde el año 2003 de 5.000 trabajadores a más 9.000 tres años más tarde.

Los movimientos de población constituyen para algunos investigadores vinculados a la perspectiva "transnacionalista" una dinámica clave dentro de la globalización. Al crecimiento de los flujos de capital, del comercio y de los productos culturales, se suma la de hombres y mujeres que constituyen redes trasnacionales con nodos de control en múltiples localidades ${ }^{9}$. Roberto Benencia, quien ha trabajado en Argentina la migración boliviana como parte del fenómeno trasnacional, señala a Basch, Schiller y Blanc Szanton (1992) como los promotores del concepto, al observar que la migración transnacional está vinculada a actuales condiciones del capitalismo global, por lo que debe ser analizada "en el contexto de las relaciones globales entre capital y

\footnotetext{
9 En el contexto de la globalización, el transnacionalismo puede ampliar las comunidades de contacto personal previamente constituidas con base en el parentesco, la vecindad o el trabajo hacia comunidades virtuales muy desarrolladas, que se comunican a distancia. Portes y sus colaboradores (1999) distinguen entre el transnacionalismo desde arriba - las actividades que son conducidas por poderosos actores institucionales, como las corporaciones multinacionales y los estados - y el transnacionalismo desde abajo -las actividades que son resultado de iniciativas de base por parte de los inmigrantes y sus contrapartes en el terruño. Las comunidades transnacionales pueden desarrollar un poder de equilibrio para oponerse al poder de las corporaciones, los gobiernos y las organizaciones intergubernamentales.
} 
Verónica Trpin

trabajo" (Benencia, 2006:140). Según Stephen Castles y Marx Miller (2004:14),

Los movimientos adoptan muchas formas: las personas emigran como obreros, especialistas altamente calificados, empresarios, refugiados o como parientes de migrantes previos. Independientemente de si la intención original es un movimiento temporal o permanente, muchos se establecen de manera definitiva. Se crean redes de migrantes que vinculan las áreas de origen y destino y ayudan a impulsar importantes cambios en los dos.

Estos autores sostienen que la mayoría de los movimientos posteriores a 1945 empezaron como migración laboral, organizados a menudo por los patrones y los gobiernos; aunque no puede desconocerse la vigencia de migraciones "no económicas", como aquellas protagonizadas por refugiados y refugiadas.

\section{La transmisión de la experiencia de los sujetos}

La persistencia de la segmentación en el mercado de trabajo en el que se encuentran migrantes limítrofes como los chilenos, puede analizarse recuperando los marcos otorgados por los estudios de las migraciones laborales (Piore, 1979).

Tal perspectiva comparte con la llamada teoría del sistema mundial la idea de que las economías altamente desarrolladas necesitan, insoslayablemente, de mano de obra foránea para ocupar lugares de trabajo en determinados sectores productivos. Desde luego, se sitúa en el mismo plano de los grandes procesos macrosociales. La explicación de la teoría del sistema mundial sobre las migraciones internacionales no reside tanto en esta demanda de trabajo, sino más bien en los desequilibrios generados por la penetración del capitalismo en países menos desarrollados. Sassen es una de las referentes más destacadas, y 
Identidades en movimiento

sus investigaciones concluyen que las migraciones refuerzan las desigualdades en lugar de contribuir a reducirlas. ${ }^{10}$

Complementar los procesos "macro" involucra también el registro de la propia experiencia de los sujetos. A través de ello, se observa la estacionalidad de sus traslados como una forma de vida y la circulación por espacios translocales como constitutivo de una identidad laboral que es transmitida y reproducida en el seno de la familia.

Estas miradas se transforman en un desafío para analizar las territoriedades ampliadas. Más aún, desde la perspectiva etnográfica considero que pueden profundizarse - tal como sostiene Grimson (2006) - las complejas vinculaciones entre clase, género y etnicidad de los procesos migratorios.

Atendiendo estas dinámicas que se encuentran orientadas por pautas culturales reproducidas a través de las relaciones cotidianas, Ludger Pries (1999:61) se pregunta:

¿de donde obtienen los actores la información necesaria para tomar las decisiones? No la adquieren a partir de análisis científicos o de datos sobre las diferencias salariales, las condiciones del mercado de trabajo y las oportunidades laborales, sino en la inmensa mayoría de los casos, mediante estructuras de comunicación reticulares de su propio ámbito cercano. Es decir, la información acerca de condiciones de trabajo y de empleo, de posibilidades de vivienda y de aspectos jurídico formales en las regiones de destino, se adquiere de manera casi exclusiva a través de las relaciones personales de confianza.

La confianza como relación personal ha sido para las familias chilenas el sustento de su llegada y de su permanencia en la zona, soporte sin el cual la propia reproducción de su condición

\footnotetext{
${ }^{10}$ El trabajo pionero de Sassen (1988) enfatizó cómo los patrones de inversión extranjera y de desplazamiento de ciertos empleos de la manufactura de Estados Unidos hacia fuera, han promovido nuevas corrientes migratorias hacia dentro.
} 
de familias trabajadores no hubiera sido posible. Sin embargo, debemos considerar a estas familias no sólo como transmisoras de información sobre condiciones de trabajo y de los modos de realización de las tareas culturales, sino también como socializadoras en una identidad laboral y chilena que se prolongó a la primera generación de hijos e hijas nacidos y nacidas en Argentina.

En trabajos anteriores (Trpin, 2004) observé que las identidades étnico-nacionales de algunas familias de migrantes limítrofes parecen haberse convertido en una identidad positiva que garantiza trabajo. Lejos de la vergüenza de pertenecer a determinados grupos nacionales, ser hijos de limítrofes posibilitó la inserción y mantenimiento en el mercado de trabajo frutícola. Incluso a algunos argentinos hijos de chilenos les permitió ir a Chile a la casa de parientes para solicitar trabajo, cuando en la Argentina se registraron históricos índices de desocupación en la década de 1990.

La división nacional del trabajo, en la que ser chileno y ser trabajador se reforzaron asimétricamente, constituyó un modo de reproducción familiar y de inserción laboral que desarrollaron los trabajadores en su cotidianeidad local. Esta reproducción familiar no se limita a prácticas meramente productivas.

Algunas familias de trabajadores rurales de origen chileno garantizaban a su descendencia argentina la posibilidad de una inserción laboral sostenida, tanto en una socialización en el trabajo como en una identidad etno-nacional chilena, en la que ser trabajador rural se tradujo como ser chileno. La etnicidad, como forma de organización de la interacción social, se expresa en estos espacios a través de categorías nacionales actualizadas por los trabajadores como adscripción a valores identificados con la cultura y cuyo contenido varía con relación al contexto (Barth, 1969). Clase y etnicidad se conjugaron de esta manera en una identidad como recurso. 
Identidades en movimiento

\section{La llegada y el conocimiento del trabajo}

Las charlas mantenidas con algunas chilenas en las cocinas de sus casas, en las chacras, son momentos que registré con detalle gracias a las horas que destinaron a contarme sobre sus vidas. Rosa fue una mis mayores confidentes, aún le realizo visitas que siempre nos alegran.

Una tarde de invierno, mientras con Rosa compartíamos unos mates dulces en la cocina de su casa, recordó las expectativas con las que salieron de Chile en 1992 para trabajar en el Valle. Roble, su marido, ya conocía la zona como trabajador temporario. El conocimiento de Roble de las ganancias que se sacaban en la temporada de fruta abonó la representación de prosperidad de la región.

Contaba Rosa que en la decisión de "venir al Valle" influyó la insistencia de uno de los hermanos de Roble asentado en la zona y la imagen de las posibilidades que ofrecía el Valle. Como en los casos de inmigración ultramarina y limítrofe (Devoto, 1992), la llegada de chilenos al Valle es en cadena: luego de conseguir trabajo, un familiar sugiere la migración de sus parientes ante condiciones económicas o políticas evaluadas como "desventajosas" en el lugar de origen. La expectativa con la que Roble y Rosa se instalaron en el Valle estaba orientada a la mejora de su situación económica, que aparecía en Chile como "inmóvil".

En el relato de Rosa se reflejaba el modo en que el deseo de conseguir mejores oportunidades laborales se abonaban con la experiencia de Roble de "venir, hacer la temporada y tener plata":

en ese momento él estaba sólo con la madre allá, sus hermanos estaban acá, entonces él venía, hacía la temporada, se iba a Chile, terminaba de pagar la casa donde vive su madre, la alimentaba a ella y ahí volvía a hacer otra temporada. Bah, alcanzaba para ayudar a toda la familia en el año. ${ }^{11}$

${ }^{11}$ Entrevista realizada el 4 de Diciembre de 2000. 
Rosa reafirmó que cuando en los años '80 Roble llegaba a la Argentina como temporario, la zona del Alto Valle ofrecía buenas oportunidades laborales. Esther, otra chilena y vecina de chacra de Rosa, contó que su madre fue la primera de la familia en venir a trabajar como temporaria a la zona; sus relatos incentivaron el deseo de migrar a los demás miembros:

mi mamá decía "tu sabes que trabajan con los tractores, llevan los cajones"; claro cuando ella vino eran cajones cosecheros, en esos años había cajones cosecheros no habían bins como ahora. Decía "los cajoncitos chiquititos juntan la manzana de las plantas" y eran chicas las plantas porque yo me acuerdo cuando llegamos acá había un cuadro ahí, ¿̇viste adelante? y eran todas plantas enanas, y las sacaba yo no con la escalera, sino que todo por abajo, entonces yo me imaginaba viste? tractorcitos chiquititos, todo, los árboles con fruta, algo lindo, algo lindo y que era todo fácil. ${ }^{12}$

La experiencia migratoria temporal de la madre de Esther constituía una referencia indiscutida para ella. La idealización de un destino en el que el trabajo "sobraba" y era bien pago era garantía de las posibilidades económicas que no les ofrecía Chile.

Porque la gente que venía acá a hacer la temporada llegaba con ropa vaquera, con zapatillas, allá las zapatillas y la ropa vaquera no se usaban. Ahora no, porque ahora uno va y está todo plagado de zapatillas y vaqueros, pero cuando llegaba uno que venía a hacer la temporada vos te dabas cuenta enseguida, porque estaba de pinta en blanco, ¿viste? con camisa de jean, campera de jean, vaqueros, todo, los "blu jenes" les decimos nosotros, entonces uno, yo me imaginaba como te digo, otra cosa, cuando llegamos a Las Lajas (al ver otro paisaje) yo ya decía entre mí: - Para que le habré dicho que viniéramos.

${ }^{12}$ Entrevista realizada el 31 de Enero de 2001. 
Identidades en movimiento

En las charlas mantenidas con Rosa y Esther se percibía la misma distancia entre lo que "se imaginaban" y lo que encontraron en el Valle. Quizá estas mujeres sufrieron cierto arrepentimiento por haber dejado atrás el país de origen en pos de perseguir un sueño de prosperidad, en un lugar en el que el clima y el paisaje se les presentó totalmente distinto. Venir de regiones de Chile en las que el bosque húmedo y las montañas dominaban la cotidianeidad a una meseta árida, donde el verde sólo se instala con el follaje de los frutales en la primavera y el verano, representó un cambio que se añora.

Las ilusiones depositadas en el nuevo lugar donde trabajarían y vivirían junto a sus esposos parecieron desvanecerse rápidamente. Del trabajo "de sol a sol" dependían las deseadas diferencias monetarias; el desgaste físico del hombre y la mujer eran parejos, a pesar de que los parientes asentados en localidades del Alto Valle colaboraron desde un comienzo en la búsqueda de trabajo y en el aprendizaje del trabajo en las chacras.

Rosa vivió con los parientes de su marido sólo un par de meses, mientras Roble trabajaba como temporario y "en negro". ${ }^{13}$ Luego obtuvo a través de un primo el puesto de encargado de chacra, lo cual le resolvió la estabilidad laboral y el problema de la vivienda. Gracias a la red familiar que actuó ante un patrón conocido, como "referente" del recién llegado, Roble consiguió trabajo. Lo mismo sucedió con Esther, quien no sólo había llegado junto a su marido sin trabajo sino, además, sin saber nada de las tareas culturales de las chacras. Sus familiares fueron necesarios también para que ambos aprendieran a trabajar en la fruticultura.

En la construcción de su pasado familiar, Rosa y Roble le asignaron un lugar importante a su ingreso a la Argentina. Como tantos otros, la pareja cruzó la frontera en calidad de "turistas", sin que ello fuera una traba para su posterior inserción laboral. Luego de transformarse en encargado de chacra, Roble demoró dos años en resolver su situación legal; las oficinas de migraciones, las

${ }^{13}$ Trabajo no registrado. 
interminables colas y la cantidad de "papeles" que se solicitaban para obtener el documento de extranjero, no lo alentaban en su decisión.

Contar con un trabajo efectivo estando como "ilegal" a Roble le imposibilitaba acceder a beneficios sociales como el cobro de la asignación familiar, los aportes jubilatorios y la obra social. Rosa en cambio, postergó hasta el 2001 la realización del suyo, ya que los trabajos realizados por las mujeres en la chacra carecen de reconocimiento legal. El hecho de Rosa no tener documento le imposibilitaba la utilización de la obra social a través de su marido, pero ella optaba por atenderse en el Hospital Público local.

Ana y Luis, otra pareja de chilenos llegaron como tantos otros migrantes en los años 60 y se conocieron en un asentamiento "periférico" de la ciudad de Neuquén. Por medio de algunos contactos con familiares que eran peones de chacras Luis comenzó a trabajar en tierras destinadas a la fruticultura ubicadas en Chimpay, propiedad de la misma firma en que trabaja actualmente.

Ana recuerda la cantidad de viajes que hacían al "principio" a Chile, porque admite que extrañaba mucho a su familia y el paisaje. Luego de haber tenido un trabajo estable, sólo iban a Chile después de la cosecha. Ana dice que no se olvida de cómo "allá" es todo más difícil, especialmente para las mujeres, porque "allá viste que a las mujeres se las vigila más, y una no trabajaba fuera de la casa". ${ }^{14}$

Las "conquistas" cotidianas que expresan las mujeres chilenas en su permanencia en la Argentina, como "trabajar con el hombre, o encontrar otros trabajos para ganar plata" son rasgos que suelen destacar como un respaldo que les permite permanecer en un país extranjero. A pesar de ello, los vínculos directos como tener una madre o un padre "del otro lado" continúan justificando los viajes que hacen hacia Chile. Los contactos con los parientes

${ }^{14}$ Registro del $1^{\circ}$ de Agosto de 2006. 
Identidades en movimiento

en Chile, tal como desarrollaré, ha sido mantenidos incluso por la primera generación nacida en Argentina.

\section{La familia trabajadora}

Pude observar la organización familiar del trabajo dentro de las chacras del Alto Valle en las visitas realizadas en diferentes momentos del ciclo productivo. En el año 2000, al llegar en el verano a una chacra en la que trabajan y residen Roble y Rosa, él estaba trabajando con el tractor y Sandro, su hijo de 14 años, sacando yuyos entre los frutales, actividad que se conoce como "guadañar". 15

Rosa había dejado pendiente su tarea de acomodar ciruelas en los cajones fruteros y los chicos más pequeños, de 8 años la niña y 6 el nene, terminaban de darle agua a la chancha en un corral ubicado a unos 60 metros de la casa. En unos pocos minutos quedó plasmada la participación de toda una familia en diferentes tareas de la producción frutícola y doméstica. Así se ponían en escena nuevamente dos elementos asociados: el trabajo y la familia; éstos aparecían juntos en los relatos sobre la llegada al Valle desde Chile, en la obtención del primer empleo, el aprendizaje de las tareas culturales y en la maximización de los recursos económicos de cada grupo familiar trabajando dentro de una chacra.

Dentro de las chacras las mujeres suelen realizar las tareas "por tanto", es decir, aquellas que se pagan según el tipo de tarea y supuestamente no por ser hombre o mujer; pero a pesar de ello, en comparación con los hombres adultos, las mujeres y chicos suelen recibir menores ingresos al final de una jornada por realizar las tareas peor pagas. A pesar de estas diferencias las mujeres y chicos toman estas actividades como un modo de obtener ingresos en efectivo para la familia.

\footnotetext{
${ }^{15}$ Registro del 20 de Enero de 2000.
} 
Una mañana, cuando llegué a la chacra, Rosa y Sandro se estaban ocupando de quemar las ramas cortadas por la poda. En mi viaje en colectivo por la ruta 22 , ya había advertido fogatas en otras chacras, y chicos y mujeres arrastrando manojos de yuyos y de ramas hacia el fuego. La "quema de podos" es una tarea que se hace "por tanto", y esa mañana, mientras el sol amagaba con calentar un poco el ambiente, los ojos de Rosa y Sandro lagrimeaban por el humo y me mostraban sus manos marcadas y lastimadas con las ramas. ${ }^{16}$

Las mujeres de los encargados -puesto de mayor jerarquía dentro de la chacra- suelen "colaborar" con el control de la fruta que cosechan los peones en el verano. En las chacras que observé las mujeres no cobraban por esta tarea, simplemente consideraban que aliviaban a su marido ayudándoles. La invisibilización del trabajo registrado de las mujeres en las chacras es un tema controvertido, que en los últimos años ha tenido cierto tratamiento dentro del sindicato UATRE. ${ }^{17}$

En una visita en el año 2006 a la chacra en la que viven Rosa y Roble registré:

El lunes cuando llegue a la chacra, Rosa me cuenta el lío que tiene con los talonarios que llenan para cada bins, que ella se ocupaba de eso, pero que le puso el número equivocado a dos peones, en vez de 1 le puso 2 y al que era 2 le puso 1 , entonces en el recuento de los bins que hizo cada uno el 1 había hecho 5 pero le figuraban 3 y al 25 en vez de 3 , obviamente el que hizo más se quejó, pero su compañero no quiso arreglar el error, así que Rosa no se va a ocupar de eso, al final ¿vos que harías? Yo me equivoqué, pero el que hizo menos tendría que decir la verdad! $!^{18}$

\footnotetext{
${ }^{16}$ Registro del 16 de Junio de 2000.

${ }^{17}$ Unión Argentina de Trabajadores Rurales y Estibadores.

${ }^{18}$ Registro del 10 de Enero de 2006.
} 
Identidades en movimiento

María, la esposa de Héctor - también migrantes chilenos -, se ocupaba de esa tarea, él me comentó que:

Ella trabaja conmigo acá, en el tema de tarjetear y eso, todos los bines acá tarjeteamos, así que ella trabaja acá conmigo, dejan los bins ahí, ella viene con el numerito, tarjetea, se le ponen dos tarjetas, después cuando viene el camión se le saca una, queda una acá, con el número de trabajador. ${ }^{19}$

De esta manera se configura una división del trabajo basada en el género: la cosecha con escalera es una tarea que desarrollan los hombres, especialmente por el peso de las mochilas recolectoras de fruta; las mujeres y los niños suelen "acompañar" haciendo el registro escrito de la cosecha o bien ocupándose directamente de la cosecha manual de las ramas más bajas o de la fruta que está en el suelo o de otras tareas consideradas "menores".

La fruta que cae de los árboles por estar muy madura o por los fuertes vientos se golpea o "machuca", se pudre en parte o se llena de gusanos; entonces se destina a los bins dirigidos a la industria de jugos y sidra junto a la fruta de baja "calidad", aquella sin tamaño o marcada por el sol, por las ramas o por alguna plaga. Los bins para industria tienen un valor inferior que los destinados a las empacadoras, por lo que la productividad de una chacra se mide a través de los bins con fruta para exportación, lo destinado a industria refleja "pérdida" o, según el discurso empresarial, refleja "defectos" en la producción que impide maximizar ganancias. Las mujeres, desde su actividad no registrada se ocupan así de la fruta considerada de descarte: una actividad de "segunda" para mano de obra de "segunda", en un juego de reforzamiento de la desigualdad.

Sara Lara (1991) considera que el empleo de mujeres, junto al de indígenas y niños y niñas en diferentes regiones de América

${ }^{19}$ Entrevista realizada el $1^{\circ}$ de Agosto de 2006. 
Latina se ha convertido "en un recurso que los empleadores utilizan para intensificar el trabajo y precarizar las condiciones laborales, ya que tales grupos sociales son considerados mano de obra barata, social y culturalmente sometidos a diferentes situaciones que se traducen en falta de mejores oportunidades de empleo" (Sánchez Saldaña, 2005:266). El trabajo no declarado de mujeres en la fruticultura parece acompañar esta tendencia.

Cabe aclarar que actualmente tareas que tiempo atrás realizaban las mujeres que residían dentro de las chacras, como criar animales de corral, ahora no está permitido en muchas explotaciones por la aplicación de las BPA (Buenas Prácticas Agrícolas). Luis y Ana, otros chilenos comentaron que la ausencia de animales para la venta o el autoconsumo se debe a que la empresa a la que pertenecen "está certificada, y los ingenieros dicen que la bosta trae pestes, ni perros se pueden tener".

Esto derivó en una complicación para las familias: ya no tienen un acceso rápido a productos frescos para realizar las comidas, deben destinar ahora parte de sus ingresos y de su tiempo al obtenerlos en el pueblo. Además, se suma la imposibilidad de conseguir alguna diferencia monetaria de la venta que realizaban las mujeres de los huevos, gallinas, pollos o cerdos a vecinos y conocidos. Aquí podemos observar cómo en su condición de mujeres trabajadoras se ha profundizado un retroceso en las posibilidades de contribuir con la reproducción familiar, situación que tiende a compensarse con el trabajo en la chacra sin ser registradas.

Incluso nuevas formas de obtener algunas diferencias monetarias por fuera del salario como trabajadores rurales se ponen en práctica. Mujeres como Rosa venden ropa -buzos de algodón, medias, remeras y ropa interior- en las otras chacras, especialmente después de finalizada la cosecha "porque sé que tienen algo de plata". Con los ahorros que aparta de las tareas culturales que realiza junto a sus hijos, encarga esa ropa a unos conocidos de Gral. Roca que compran en Buenos Aires. Por su parte, su vecina Esther teje prendas con hilo traído desde Chile y 
Identidades en movimiento

comentó que "en unas semanas hago varios saquitos para niños que los cobro 15 pesos, así voy juntando algo para después ir a Chile de visita". Otras mujeres se emplean como domésticas de casas de las ciudades cercanas o venden productos cosméticos a través de catálogos. Durante visitas a escuelas rurales también se encontraron mamás de alumnos que viven en las chacras trabajando como cocineras o porteras. Todos los ingresos "extras" suelen ser destinados para los viajes a Chile, para ver a "la familia”.

\section{Hijos e hijas argentinos pero un poco chilenos}

La investigación del proceso de reproducción de la chilenidad en descendientes de migrantes chilenos, se inició en la escuela primaria $\mathrm{N}^{\circ} 68$, donde conocí a los alumnos, algunos de ellos descendientes de chilenos. Con ellos trabajé a lo largo de 1998 y 2000 bajo la dinámica de un Taller de Historia Oral. En la escuela pude observar la relación que establecen estos chicos con sus maestros que, en algunos casos, pertenecen al sector chacarero de Guerrico. Al tiempo que los chicos manifestaban su chilenidad, eran los mismos maestros los que los identificaban de este modo.

La adscripción y autoadscripción de estos argentinos a la categoría de chilenos es parte de las relaciones sociales que tienen lugar en el proceso de reproducción del trabajador frutícola, proceso donde se conjugan el trabajo, tal como señalé, junto a la familia. Desde su socialización familiar los descendientes de chilenos etnifican su lugar de trabajadores mientras que al trabajar ratifican su nacionalidad. En este doble juego co-producen su relación de subalternidad no sólo entre las dos nacionalidades medulares del contexto patagónico, la argentina y la chilena, sino también entre las dos clases sociales del sistema capitalista, dueños de los medios de producción y vendedores de fuerza de trabajo.

La reproducción de una división nacional del trabajo donde ser chileno y ser trabajador se refuerzan asimétricamente, no es el 
producto de actos discursivos inmoralmente discriminatorios de parte de los productores europeos y de los agentes locales del Estado (maestros, agentes sanitarios), sino de las relaciones de socialización y poder en las que participan maestros, patrones y familias de diverso origen en la escuela, la chacra, los caminos secundarios, los almacenes y los lugares de esparcimiento. En estos sitios de la cotidianeidad de los pobladores es donde argentinos, chilenos y gente de otras nacionalidades, reproducen como significativa y vigente la categoría de "chileno" como recurso de inserción laboral.

Ser trabajadores de chacra se revelaba, entonces, como una adscripción íntimamente vinculada con ser chilenos y permanecer dentro de esa clase implicaba no sólo conocer el trabajo sino también reproducir cierta chilenidad. De esta manera lo comentó Juan, un chico de la escuela:

como estén cubiertos (con el personal necesario) o no en la chacra se van a otra o se quedan ahí mismo, pero generalmente se van a trabajar a otro lado, o le ayudan al padre, a cosechar... Todos los pibes (mayores de 13 años) que conozco no van más a la escuela y están todos trabajando, porque a través del padre consiguen, por referencias, por chilenos, pero todos tiene que tener documento.

Esta relación entre socialización en el trabajo y familia, pude observarla en la siguiente generación de trabajadores rurales, como en el caso de Sandro, hijo de Rosa y Roble. En la chacra en la que vivía participaba en el aprendizaje de las tareas de chacra junto a su padre, cuando se realizaban los respectivos trabajos correspondientes a cada estación: la poda, el raleo y la cosecha.

El trabajo del personal permanente y temporario, que en esta chacra era íntegramente chileno, se complementaba con otras tareas realizadas por chicos y mujeres, generalmente de la unidad doméstica. De este modo, en algunos períodos del año, Sandro estaba no sólo con su familia, sino también con otros trabajadores 
Identidades en movimiento

chilenos. Su temprano ingreso a la adultez se revelaba en el modo de hablar de Sandro en la escuela y dentro de la chacra: aquí empleaba expresiones como "harto cansado", "para recuperar fuerza hay que comer naco", "chucha que iba fuerte...", "al tiro iba cosechando...", o el arrastre de las vocales al pronunciar algunas palabras, que lo mostraban más chileno.

Lengua, habla y actividad denotaban la chilenidad del trabajo en la chacra. Las expresiones "chilenas" respondían al trabajo y revelaban su sentido en las prácticas de la jornada laboral. La palabra transmitía el conocimiento del trabajo, tanto el conocimiento práctico como el teórico, esto es, los valores y normas asociados a él.

Según Roble los cinco empleados con los que compartían el trabajo y que hacían la temporada de fruta en esta chacra estaban declarados y los patrones tenían la obligación de convocarlos anualmente para cada cosecha.

En este caso, al ser trabajadores trasandinos se les avisaba que debían presentarse en la región a través de radios chilenas o telefónicamente. Los patrones tenían la precaución de convocarlos ya que, en caso de no hacerlo, los trabajadores temporarios podían presentarse en la chacra y exigirles el pago de su temporada. Roble me enfatizó en varias oportunidades que "es derecho del obrero que lo llamen" o que "si es compañero chileno hay que guardarle el lugar", demostrando cierta lealtad con sus connacionales trabajadores. El reconocimiento de su adscripción como trabajador y chileno diferenciado de los intereses del patrón que "siempre dicen que no tienen plata, pero después se van de viaje..." revelaba cierta asociación entre clase y nación.

La representación de que el chileno es un "buen trabajador" que nunca "pide de más" es una construcción que se erige en oposición a los trabajadores temporarios que llegaban del norte argentino. La chilenidad garantiza la disciplina de trabajo como un atributo a destacar frente al empleador, como una manera de presentarse en oposición a la connotación peyorativa que a veces transmite "ser chileno" en la Patagonia. "Chileno pero laburante" 
suele escucharse dentro de las chacras, transformándose en una garantía tanto de conocimiento como de compromiso con las tareas asignadas.

Desde estas señales es que familia, trabajo y chilenidad se fueron entrecruzando desde el trabajo de campo, pudiendo concluir que así como los migrantes que llegaron desde Chile al Alto Valle necesitaron de algún pariente para conseguir trabajo "por referencia" y aprender las tareas en las chacras, los chicos hijos de chilenos también se vieron involucrados en el aprendizaje del trabajo a través de la familia. A los recién llegados a la zona "ser chilenos" les facilitó el acceso laboral; a sus hijos "ser argentinos" no les garantizaba tener trabajo, por lo que reproducir en ellos cierta chilenidad y sus lazos con los connacionales de los padres contribuyó a ratificar su lugar de chilenos trabajadores de la fruta.

El lugar de los hijos de chilenos en la chacra es el de "chicos", en tanto trabajadores y aprendices de trabajadores que se incorporan como mano de obra a veces sin sueldo o con remuneraciones inferiores que los adultos. Sentirse parte de una clase distinta a la del patrón implicó no sólo definir intereses diferentes sino también, en este caso, mantener cierta fidelidad a sus orígenes nacionales. Por eso la chilenidad en la chacra se expresaba en la posibilidad de tener un puesto de trabajo por ser connacional, portar apellido chileno, hablar como chileno y demostrar que se sabía trabajar como chileno, garantizándose así como un "buen peón".

Los chicos por ser hijos de... o haber aprendido el trabajo con... sustentan un pasaporte necesario en el momento de conseguir trabajo en el sector. La conciencia de Roble de que "a un chileno hay que guardarle un lugar" se traslada a la próxima generación: considerar chilena a la descendencia argentina era reconocerla como trabajadora que legítimamente realizaba las tareas culturales de las chacras frente a la competencia "norteña" argentina. 
Identidades en movimiento

\section{Las tensiones identitarias}

Sin embargo, cabe preguntarse cómo funciona esta adscripción en otros contextos. Luego del 2001, ante altos índices de desocupación muchos chilenos volvieron a su país de origen, incluso algunos chicos, que había conocido en la escuela rural probaron suerte en el país de origen de sus padres.

Un trabajo basado en estadísticas chilenas del año 2002 muestra el proceso migratorio de argentinos hacia Chile. El informe sostiene que aunque la magnitud absoluta de inmigrantes es la mayor en la historia de Chile, el porcentaje que comprende la población de los nacidos en el extranjero sobre la población total del país sigue siendo ostensiblemente pequeño, apenas superior al 1\%, 185.000 personas, de las cuales los argentinos representan el $26 \%$ de población nacida en el exterior. "Hay indicios de suponer que la inmigración de personas nacidas en Argentina se debe en parte importante al retorno de chilenos con sus hijos nacidos en el país trasandino" (Martínez Pizarro, 2003:30). Esto se refleja en las edades de los argentinos, con mayor concentración de argentinos como menores de 15 años y de 15 a 20 , y no en las edades comprendidas entre los 20 y 50 dominantes para otras migraciones latinoamericanas.

En el 2002 después de la cosecha, cuando fui a lo de Rosa y Roble Sandro no estaba. Había dejado de asistir al colegio secundario y fue a Chile, a lo de su abuela materna a "ver que pasaba allá". Meses más tarde Sandro volvió "porque no me hallé" fue su respuesta cuando lo encontré en la chacra en la que se crió. En ese momento había encontrado trabajo en la propiedad frutícola de un patrón vecino, así que Rosa le estaba buscando una cama para que se llevara, además de utensilios para la cocina. La familia funcionaba de nuevo como soporte para la inserción de un nuevo trabajador rural.

En Argentina Sandro parecía chileno, pero en Chile "hablaba con el "che", y no me hallaba". 
Mientras Sandro me comentaba esto, Rosa me mostró fotos de su hijo menor, Eric, que para una fiesta en la escuela bailó una cueca $^{20}$ vestido con ropa "típica de Chile". Rosa se emocionaba al ver a su hijo bailando "porque a él le encanta bailar y cantar cueca", incluso unos migrantes chilenos que forman parte de un grupo de baile "chileno" de la ciudad de Gral. Roca, le iban a enseñar algunos pasos más. El orgullo con el que habla Rosa se reflejaba en su voz y en acercarme todas las fotos en que sus hijos estaban en Chile o vestidos con los trajes típicos ${ }^{21}$. Su vinculación con Chile seguía reproduciéndose en una proyección en los hijos, al tiempo que ellos no la rechazaban.

Los diversos sentidos que adquieren las identidades como parte de los fenómenos migratorios encierra una complejidad que en el caso analizado debe comprenderse en el entramado de una dinámica socioeconómica cambiante.

La construcción de las identidades de las familias de migrantes no reproduce una pertenencia original sino que dialoga con nuevos contextos y en nuevas condiciones. Sin embargo, la familia constituye el soporte para su reproducción a lo largo del tiempo.

La etnicidad - y la adscripción nacional como una de sus formas de expresión - constituye una marca de identidad potencial que puede ser tomada y movilizada cuando resulta conveniente a los propósitos de un encuentro particular (Wallman, 1979). La "nacionalidad", objetivada en la letra formal de las documentaciones personales, puede entonces, ser ocultada, tergiversada o transformada en función del contexto (Barth 1969). "Chileno" y "argentino" son gentilicios que denotan a simple vista el haber nacido en un país determinado. Sin embargo, en espacios de interacción y encuentro como el trabajo o la familia constituyen una frontera difusa, articulada de algún modo a la pertenencia

\footnotetext{
${ }^{20}$ Baile tradicional chileno.

${ }^{21}$ Registro del 11 de Octubre de 2002.
} 
Identidades en movimiento

nacional pero también a identidades sociales que exceden el lugar de nacimiento.

Específicamente en el caso de la etnicidad, podemos pensarla como procesos de reconocimiento de diferencias significativas entre nosotros y ellos, que pueden expresarse grupalmente (entre muchas posibilidades) como adscripción nacional que organiza las relaciones sociales, e individualmente como minuciosas diferencias de conducta que organizan la experiencia (Wallman, 1979). Esta idea adquiere relevancia al momento de analizar el caso de las familias migrantes chilenas, en tanto encuentro desde el cual diferentes rubros laborales performan las relaciones étnico-nacionales a la vez que son performados por ellas (y no se agotan como sería esperable de manera exclusiva en los términos económicos de intercambio e identificación).

A la vez, se pone en juego todo un sistema clasificatorio que relaciona dialéctica y contextualmente contrapuntos como nativo - extranjero al mismo tiempo que un uso pragmático que por momentos congela, esencializa, reifica estas mismas identidades, asumiendo correspondencias entre lo etno-nacional y determinadas características morales y de conducta, fundamentalmente en virtud de los procesos de demarcación de límites intergrupales y de las estrategias de expresión y negociación de conflictos (Trpin y Vargas, 2005).

Escribía Barth en 1969 que "los grupos étnicos son categorías de adscripción e identificación que son utilizadas por los actores mismos y tienen, por tanto, la característica de organizar interacción entre los individuos". Es así como, dependiendo de las percepciones de los actores, y los constreñimientos y oportunidades del contexto en el cual ellos actúan, la etnicidad puede ser un recurso positivo, negativo o resultar indiferente $y$ revestir sentidos diversos según el momento y los involucrados. 
Verónica Trpin

\section{Referencias bibliograficas}

ABRAMO, Lais y ABREU, Alice Ranger de Paiva. (orgs.) Gênero e trabalho na sociologia latino-americana. Serie II. Congresso Latino-americano de Sociologia do Trabalho, São Paulo, ALAST, 1998.

ARANGO, Joaquín. La explicación teórica de las migraciones: luz y sombra. Revista Migración y desarrollo, $\mathrm{n}^{\circ}$ 1, 2003 (www.migracionydesarrollo.org).

BANDIERI, Susana. (coord.) Cruzando la cordillera... la frontera argentinochilena como espacio social. Neuquen, CEHIR, 2001.

BARTH, Fredrik. Los grupos étnicos y sus fronteras. México, Fondo de Cultura Económica, 1969.

BASCH, Nina; Glick SChILler, Lila y BlanC Szanton, Cristina. Transnacionalism: a new analitic framework for understanding migration. Annals of the New York Academy of Science, vol. 645, 1992 [reedición de "Toward a transnational perspectives on migration"].

BENDINI, Mónica y Radonich, Marta. (coords.) De golondrinas y otros migrantes. Buenos Aires, La Colmena, 1999.

BENENCIA, Roberto. El fenómeno de la migración limítrofe en la Argentina: interrogantes y propuestas para seguir avanzando. Estudios Migratorios Latinoamericanos, $\mathrm{n}^{\circ} \mathrm{s} 40-41,1998 / 1999$.

Bolivianización de la horticultura en la Argentina. Procesos de migración transnacional y construcción de territorios productivos. En JELIN, Elizabeth y GRIMSON, Alejandro. (com.) Migraciones regionales hacia la Argentina. Diferencia, desigualdad y derechos. Buenos Aires, PROMETEO, 2006.

BOURDIEU, Pierre. El sentido práctico. Madrid, Taurus, 1991.

BRUMER, Anita y PIÑEIRO, Diego. (orgs.) Agricultura latino-americana. Novos arranjos e velhas questões. Porto Alegre, UFRGS, 2005.

CASARAVILlA, Diego. Los laberintos de la exclusión. Relatos de inmigrantes ilegales en Argentina. Buenos Aires, Editorial Lúmen, 1999.

CASTLES, Stephen y MiLleR, Mark. La era de la migración. Movimientos internacionales de población en el mundo moderno. México, Universidad Nacional de Zacatecas, 2004. 
Identidades en movimiento

DEVOTO, Fernando. Movimientos migratorios: historiografía y problema. Buenos Aires, CEAL, 1992.

GRIMSON, Alejandro. Nuevas xenofobias, nuevas políticas étnicas en la Argentina. En: JELIN, Elizabeth y GRIMSON, Alejandro. (com.) Migraciones regionales hacia la Argentina. Diferencia, desigualdad y derechos. Buenos Aires, PROMETEO, 2006.

GUBER, Rosana. La etnografía. Método, campo y reflexividad. Buenos Aires, Grupo Editorial Norma, 2001.

KLOSTER, Elba y otros. Migraciones estacionales en el Alto Valle de Río Negro y Neuquén en el último decenio. Mimeo, Neuquén, Universidad Nacional del Comahue, 1992.

LARA FLORES, Sara. Las obreras agrícola: un sujeto social en movimiento. Nueva Antropología, $\mathrm{n}^{\circ}$ 39, México, Universidad Autónoma de México, 1991.

LOPEZ, Arturo; CoRTeZ Ruiz, Carlos; GuzMAn GOMEZ, Elsa y otros. (coord.) Cultura e identidad en el campo latinoamericano. México, Universidad Autónoma Metropolitana, 1999.

PIORE, Michael. Birds of passage: migrant labor and industrial societies. Cambriedge, Cambriedge University Press, 1979.

PORTES, Alejandro. Conclusion. Towards a new world: the origins effects of transnational activities. Ethnics and racial studies 22:2, 1999.

PRIES, Ludger. La migración internacional en tiempos de globalización. Varios lugares a la vez. Revista Nueva Sociedad, n 164, Venezuela, Nueva Sociedad, 1999.

SANCHEZ SALDAÑA, Kim. La experiencia de niños y niñas en la migración estacional de jornaleros agrícolas en México. En: BRUMER, Anita y PIÑEIRO, Diego. (orgs.) Agricultura latino-americana. Novos arranjos $e$ velhas questoes, Porto Alegre, UFRGS Editora, 2005.

SASSEN, Saskia. The mobility of labour and capital. Cambriedge, Cambriedge University Press, 1988.

SCHIAVONI, Gabriela. Parentelas y unidades domésticas. Las relaciones familiares de los ocupantes de la frontera agraria (Marabá-Brasil y Misiones-Argentina). Documento de Trabajo, Posadas, Universidad Nacional de Misiones, 1998. 
StOLEN, Kristi Anne. La decencia de la desigualdad. Género y poder en el campo argentino. Buenos Aires, Antropofagia, 2004.

SUAREZ NAVAS, Liliana. Dinámica y política de invisibilidad. Ley, vigilancia y racionalización de agricultura. Migraciones, $\mathrm{n}^{\circ} 4$, Madrid, Universidad Pontificia de Comillas, 1998.

TRPIN, Verónica y VARGAS, Patricia. Migrantes y trabajadores en la Argentina: la etnicidad como recurso. Anuario de Estudios en Antropología Social, Buenos Aires, Antropofagia/IDES, 2005.

TRPIN, Verónica. Aprender a ser chilenos. Identidad, trabajo y residencia de migrantes en el Alto Valle de Río Negro. Buenos Aires, Antropofagia, 2004.

WaLLMAN, Sandra. (ed.) Ethnicity at Work. London, The Macmillan Press LTD, 1979.

Woortmann, Ellen. Herdeiros, parentes e compadres. São Paulo/ Brasilia, Hucitec, 1995. 